\title{
Picture this: Managed change and resistance in business network settings
}

\author{
Hanne Kragh, Assistant Professor, PhD \\ Aarhus School of Business, University of Aarhus \\ Department of Management \\ Email: hak@asb.dk \\ $\&$ \\ Poul Houman Andersen, Professor, PhD \\ Aarhus School of Business, University of Aarhus \\ Department of Management \\ Email:poa@asb.dk
}

Competitive paper presented at the IMP Conference, Uppsala, 4-6 Sep 2008

Please do not cite or quote without authors' permission

\begin{abstract}
This paper discusses change management in networks. The literature on business networks tends to downplay the role of managerial initiative underlying the proactive attempts of single actors to install network changes. The change management literature addresses such managerial initiative, however, with its single firm perspective overlooks the interdependence of network actors and relationships. Taking departure in the void between these two streams of literature, we deploy the concept of network pictures to discuss how managers interpret change projects and attempt to manage change in network settings. We analyze a change project from the furniture industry involving multiple actors and address the consequences of attempting to manage change activities in a network context characterized by limited managerial authority over these activities. Our analysis suggests that change efforts rather than being projects mastered by the initiating actor unfold as a negotiated process during which the change project is re-negotiated to fit the multiple actor constituencies. The degree of overlap in the co-existing network pictures of the involved actors is found to be decisive for the possibility to successfully implement network change.
\end{abstract}

\section{Keywords:}

Network change, change management, network pictures, routines, organizational resistance 


\title{
Picture this: Managed change and resistance in business network settings
}

\begin{abstract}
This paper discusses change management in networks. The literature on business networks tends to downplay the role of managerial initiative underlying the proactive attempts of single actors to install network changes. The change management literature addresses such managerial initiative, however, with its single firm perspective overlooks the interdependence of network actors and relationships. Taking departure in the void between these two streams of literature, we deploy the concept of network pictures to discuss how managers interpret change projects and attempt to manage change in network settings. We analyze a change project from the furniture industry involving multiple actors and address the consequences of attempting to manage change activities in a network context characterized by limited managerial authority over these activities. Our analysis suggests that change efforts rather than being projects mastered by the initiating actor unfold as a negotiated process during which the change project is re-negotiated to fit the multiple actor constituencies. The degree of overlap in the co-existing network pictures of the involved actors is found to be decisive for the possibility to successfully implement network change.
\end{abstract}

\section{Keywords:}

Network change, change management, network pictures, routines, organizational resistance 


\section{Introduction}

In a globalizing and increasingly disruptive business context, change capabilities are critical for gaining and sustaining competitive advantage (Kumar, Scheer, \& Kotler, 2000). At the same time, companies are increasingly extending their partnerships with buyers and suppliers in order to leverage their strategic flexibility and focus their competencies (Afuah, 2000; Lei \& Slocum, 1992). The value-adding activities of one firm are therefore increasingly dependent upon the activities of other firms in the network. This interdependence creates a paradox for firms' ability to implement changes in their current activity networks. On the one hand, inter-organizational networks provide companies with some flexibility in terms of access to external resources and extended opportunities compared to what a company can build up on their own (Dyer \& Singh, 1998). On the other hand, they also limit the discretion of individual actors, who must act in accordance with the vested interests of their network and therefore may not be able to implement change that conflicts with these interests (Krackhardt, 1994).

IBM provides an ample example of this dilemma: Through collaboration in networks, IBM has been able to leverage strategic flexibility in a number of projects, where volatile market conditions has demanded swift introduction of new technologies, such as in the introduction of the Personal Computer, and latest in their introduction of the Blade technology, where an open standard architecture is used to establish a collaborative community of suppliers and users (www.Blade.org). However, IBM failed in their attempt to muster network partners in a radical change process involving the introduction of the OS/2 operating system as a competitor to Microsoft Windows. Rather than going with OS/2, suppliers and customers decided to stick with the established PC architecture that worked with the existing DOS operating system (Chesbrough \& Teece, 2002). In other words, the complementary resources in networks are both a source of innovation and strategic flexibility and an obstacle for implementing radical change, when such change calls for the redefinition of roles and positions of other members in the network.

The constraining effects of networks upon change projects are seldom addressed in the change management literature. Here, change management is typically defined as "the process of modifying or transforming organizations in order to maintain or improve their effectiveness" (Hayes, 2002). It takes departure in a single firm perspective, where management is assumed to exercise authority over the deployment of existing activities and resources within the firm and overlooks external contingencies upon the implementation of projects initiated by single actors. The fact that the implications of the firm's external dependence on wider resources vested in networks are not part of the change management literature means that this literature cannot be readily applied in order to understand the challenge of change management in a network setting.

Whereas the contingencies of business relationships with external actors play an important role in the business network literature, this strand of literature tends to ignore the role of managerial initiative in pursuing change. Hence, it does not discuss the role of single organizations as change agents in a network context, whether successful or not. Network change is largely discussed in terms of the structural tension between stability and dynamics in exchange systems (Gadde \& Håkansson, 1992; Gadde \& Mattsson, 1987; Håkansson, 1992; Håkansson \& Henders, 1995). For instance, Henders and Håkansson depict network dynamics as "a force of their 
own...actors have limited resources with which to engage in change activities" (1995:142-143). Also, change is often discussed in terms of dyadic adaptations, i.e. behavioral or organizational modifications which one organization carries out to meet the needs of another organization (Brennan, Turnbull, \& Wilson, 2003). Adaptations are made gradually during the development process of a relationship and sometimes may take place almost implicitly in the course of day-to-day operations (Håkansson \& Snehota, 1995; Johanson \& Mattsson, 1987). Consequently, the concept of adaptations can be used to explain commitment and dependence between network actors; however, due to its predominantly reactive nature it is less useful for discussions of attempted network change initiated proactively by a single actor in accordance with the visions and ideas of that actor. Hence, in terms of change, the business network literature portrays a largely deterministic approach with little room for managerial initiative.

However, despite their resource and activity embeddedness in network contexts, single actors have strategic agendas and do take change initiatives, as shown in the IBM example. However, in doing so, they are also met with challenges that emanate not only from within organizational boundaries, but span into their wider network context. On that background, we believe that managed change in networks is a change activity that needs specific theoretical treatment. Business networks consist of unique and interdependent actors, motivated by their own issues and with heterogeneous interpretations of what is possible and feasible within a network setting (Ford \& Håkansson, 2006). Attempts to manage network change unfold in a context of distributed influence with limited managerial authority and possibilities for controlling change activities and where actors are embedded in multiple relationships. This suggests that such change efforts - rather than being projects mastered by a single change agent - unfold during a negotiated process involving multiple actor constituencies and where the outcome of a change project may not be in concert with intentions. Consequently, we seek to explore the following issue: how does the interdependence of network actors impact on managerial change efforts? We address this issue using the case of network change following from the introduction of Internet-enabled ICT into the inter-organizational relationships of a network. The implementation of Internet-enabled ICT is a suitable case, because it represents a change that is potentially fundamental enough to break the existing institutionalized structures of a network and therefore may result in substantial shifts in network structure and practices. Through discussion of the specific conditions for change that exist in a network, the aim of the paper is to further the understanding of how change unfolds in a network context and subsequently, from a management point of view, to point to critical issues when managing network change processes.

\section{Network pictures of routines}

Generally speaking, organizational change concerns a shift from one organized pattern of behavior to another. Here, we understand such organized patterns of behavior in terms of organizational routines. Basically, an organizational routine describes a sequenced pattern of activities performed to achieve a specific aim. Routines have long been acknowledged as an important element of understanding organizational action (Feldman, 2003). Emphasizing their stable nature, routines can be viewed as 'repeated patterns of behaviour that are bound by rules and customs and that do not change very much from one iteration to another' (Feldman, 2000:611). 
Although a business network is not an organization in a traditional sense, it may be described as a system of ordered patterns of exchange (Snehota, 1993). Comparable to what Alderson (1957) describes as an organized behaviour system, network actors are positioned, related and interdependent as a consequence of constrained, but deliberate behaviour, where organizing is self-imposed by members paying heed to exchange possibilities in selective ties with other actors. Used in a business network context, routines are used to coordinate the activities of individuals within interacting companies (Andersen, 2003). They reflect how actors in their attempts to minimize the costs associated with this coordination have come to agree on certain operating procedures (Håkansson \& Snehota, 1995). These procedures give stability to the relationship and direction to recurring activities within it (Cyert \& March, 1963).

Our understanding of how business managers interpret change possibilities and attempt to manage change in network settings builds on the concept of network pictures. Network pictures capture how actors make sense of the surroundings in which they are integrated and as such are subjective mental representations of the contexts of managers, which accordingly shape the underlying subjective logic for managerial action (Henneberg, Mouzas, \& Naudé, 2006). Building on the assumption that individual managerial action must be seen as embedded within interorganizational relationships, the literature on network pictures is particularly interested in the connection between the inter-organizational exchanges within which management actions are embedded and the beliefs and attitudes which actors hold about them (Öberg, Henneberg, \& Mouzas, 2007). A critical component in a network picture therefore is the mental representations held by managers of the roster of routines that it is possible to evoke in any given network setting. Recently, there has been an increased interest in the conceptualization of the underlying dimensions of network pictures by researchers concerned with managing in networks (Henneberg, Mouzas, \& Naudé, 2006; Öberg, Henneberg, \& Mouzas, 2007). Although contributions differ, for instance, with respect to the actual dimensions of a network picture addressed and methodology suggested, they agree that network pictures are ends-oriented and used by managers with some purpose in mind (Henneberg, Mouzas, \& Naudé, 2006). Individuals unconsciously include in their frameworks what they hold to be relevant and therefore, network pictures indicate what managers understand as important about the environment of their company. As the framing of network pictures is based on individual experience, relationships and position and furthermore is affected by individual limits to knowledge and understanding, a network contains a variety of different network pictures (Ford et al., 2003).

In the present context, a network picture of routines held by an individual manager is an interpretation of the logic behind the business model currently performed by the actors involved in the network. It includes an interpretation of how roles are distributed among network actors in order to create and deliver value to customers as well as an idea on how value is captured by involved actors and what activities are deemed critical in this process. Network pictures frequently differ across managerial mind sets for at least two reasons. First, distribution of value adding activities in any market setting frequently also entails a distribution of knowledge, which no one understands in its totality (Hayek, 1945). As it is too complex for any individual to grasp the complete range of routines existing within a network, the network pictures of managers are simplified versions of this totality. Consequently, managers may be unaware of specific activities performed by other actors and they may disagree with regards to the importance of these activities. Second, actors may value the roles they 
perform in relation to a network routine differently, because actors are vested in multiple, complex network settings. For instance, adding or subtracting an activity to a specific activity configuration held by an actor may provide a possibility for capturing value which goes beyond the value related to performing that specific activity. For instance, furniture dealers may find it valuable to carry a prestigious line of designer furniture to add an attractive breadth to their existing selection, even though customers mainly select the less expensive items.

\section{The case}

The case studied is the export marketing system of Danish furniture manufacturer Fritz Hansen, who sell exclusive design furniture in more than 40 countries worldwide. Fritz Hansen seek to associate their products with a certain lifestyle and values promoted through storytelling and close cooperation with design communities on various markets. Products are being sold to the private and professional markets through a network of independent dealers. Fritz Hansen operate a regional structure and their strategy is to be present with sales subsidiaries in all major sales regions. These regional offices manage the relationship with the dealer network on the different local markets.

Following a period characterized by a strong focus on rationalization and optimization within production and sourcing, at the time of data collection, the strategic focus of Fritz Hansen was increasingly on the strengthening of their international profile through an increased focus on sales and global branding. This process included a clear strategy for how Fritz Hansen wished to work with their international dealer network. The partnership strategy was supported by a range of different Internet-enabled tools. The introduction of these tools meant considerable changes in the (intended) configuration and management of the relationship between Fritz Hansen and their local dealers, which in turn put pressure on the change ability of the different network actors.

The network studied including actors and relationships is illustrated in Figure 1. The Figure includes an additional element labelled the Partner Portal. The Partner Portal is at the centre of the change project studied and will be discussed in detail after an introduction to the research design applied. 


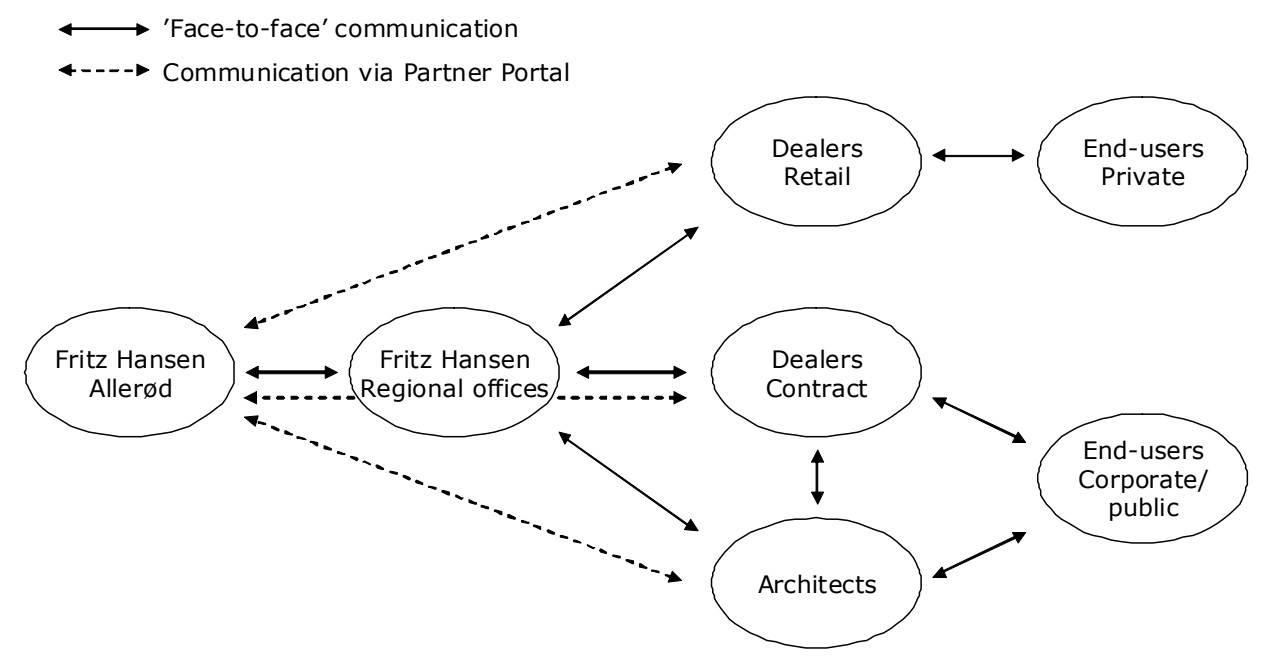

Figure 1. Network actors and relationships

\section{Methodology}

In order to study the impact of Internet-enabled ICT on activity configuration and routines in the relationships of a network, we adopted a case study strategy. The case focused specifically on changes taking place in the relationships between companies and on related changes in network structure and did not address intra-organizational change.

It has been suggested that discrepancies between the understandings of different network actors contributes to understanding change in networks and particularly differences between the initial intentions and the actual outcome of a change project (Ford \& Håkansson, 2006). On that background, a key property of the research design applied is that within a network setting, the network pictures of individual actors are important to understand network change. We were therefore particularly interested in addressing how different individuals frame a change project based on their particular role within a network and the value creation logic emanating from their understanding of this role. Accordingly, a network is regarded as the product of social interactions among network actors basing their interactions on individual, subjective framings conceptualized as network pictures; a view in accordance with social constructionism (Berger \& Luckmann, 1966; Henneberg, Mouzas, \& Naudé, 2006).

The field study period extended from January to September 2005. During this period 21 interviews were conducted within the export marketing system of Fritz Hansen. Interviews were conducted at Fritz Hansen headquarters in Denmark as well as at their regional offices in Italy, Germany and the US. Furthermore, at these locations, a number of independent dealers and architects targeting the contract and/or the retail markets were interviewed. Geographical locations were chosen to represent different degrees of market penetration, different stages of formal introduction to the change project, and different levels of e-readiness of the countries in question (Economist Intelligence Unit, 2005); all of which were expected to potentially influence local market actors' understandings of the change project and consequently, their ability and willingness to change. 
Sampling and interviewing fell in two separate stages. During the first stage, focus was on collecting background information about Fritz Hansen and their use of ICT in general and within marketing in particular. Informants included different managers at headquarters in order to obtain a detailed understanding of the change project studied and how it was understood and positioned within different departments. The second stage included field trips to Germany, Italy and the US in order to discuss the understanding and subsequent use of the Partner Portal project with local Fritz Hansen staff including managers and sales consultants as well as with sales managers at the dealers and architects whom the project was targeted at.

The interviews were semi-structured and relied on four different interview guides for use at Fritz Hansen headquarters, architects, dealers (retail and contract), and regional offices, respectively. Interviews were recorded and transcribed. Transcripts were subsequently sent to informants along with a separate document containing those passages from the interview that had been singled out for quotation in order to ensure that informants recognized our assessment of their understanding of the change project (Kvale, 1995). This was further ensured by sending the case draft to our contact person for a review, which caused no major comments.

\section{The Partner Portal project: introducing new routines into the network}

The change project studied is referred to as the Partner Portal project. Introduced in 2004, the Partner Portal is a password-protected collection of Internet-enabled tools located at Fritz Hansen's website and targeted at supporting the relationships with the company's dealers.

As illustrated in Figure 2, the purpose of the change project was to use the Internet to reshuffle activities and information within the network in a way where the creation and storage of information would be increasingly centralized at Fritz Hansen's headquarters, whereas searching for and accessing information would be left to the dealers who would benefit from the increased flexibility of being able to access information whenever convenient.

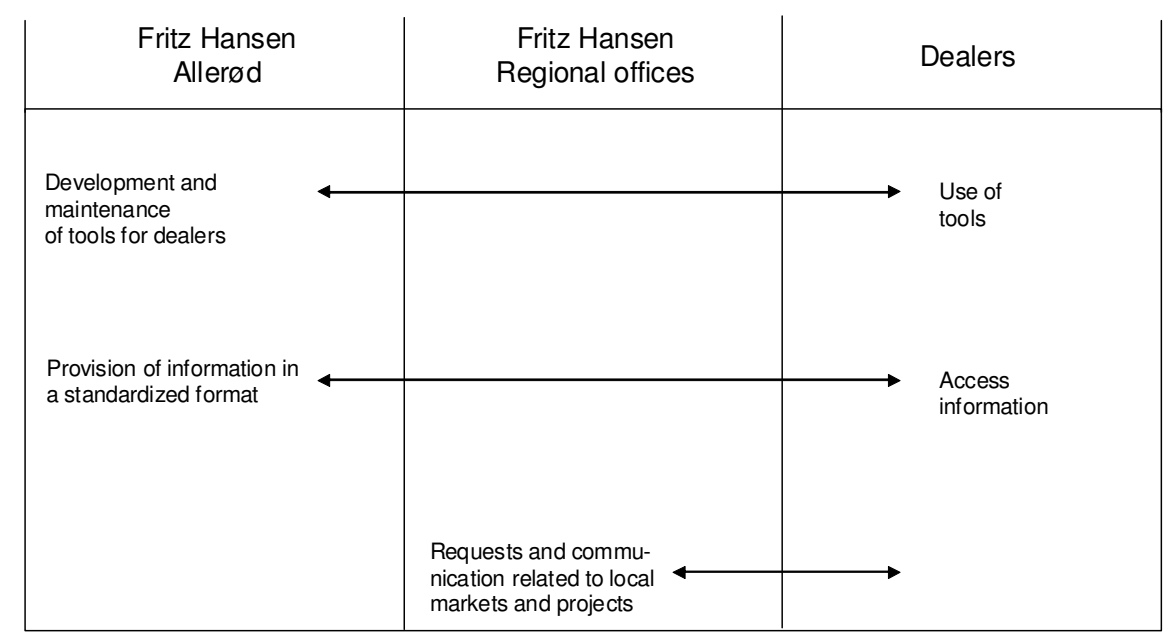

Figure 2. Plans for the use of the Internet to support export intermediation activities 
The decision on behalf of Fritz Hansen to develop the Partner Portal in the first place was closely tied in with the company's overall strategy for how to work with their local dealers. This partnership strategy was characterized by a dual focus on increased standardization of the relationship between Fritz Hansen and their dealers through, for instance, the introduction of yearly collections, uniform requirements in terms of minimum purchases and shop layout, and rationalization of the provision of product information on the one hand, and the wish to create a strong commitment to individual dealers on the other. Whereas the introduction of Internet-enabled tools first and foremost attempted to capitalize on a key property of Internet technology, i.e. the ability to re-use resources and standardize activities across a wide range of business partners and relationships and, hence, was mainly related to the aim of increasing standardization of relationships, it was also intended to contribute to signalling increased commitment to the dealer network.

The anticipated activity reshuffling and redefinition of roles and responsibilities within the export marketing system of Fritz Hansen as a result of the use of the Partner Portal were realized to a lesser degree than expected. During the initial stages of the change project, which we studied, the portal did not become a fully integrated part of the relationship between Fritz Hansen and their dealers, who were somewhat reluctant to take up the portal. This initial reluctance was especially pronounced for those parts of the Partner Portal that required more significant changes of daily practices on behalf of potential users, such as, for instance, the more interactive elements as well as elements requiring the use of a password, according to a Fritz Hansen sales consultant.

...then the partners said - each supplier has something like this and we cannot remember all these passwords and codes and how to deal with this and this and they were a little bit sceptical.

Sales Consultant, Fritz Hansen

Elements such as product information, images and ordering of marketing material were more readily used. As such, a gradual implementation process, where parts of the Partner Portal were taken up by dealers in effect substituted for the instant, comprehensive use initially expected.

The change project reflects a number of difficulties related to introducing new practices into existing relationships and the resistance that is met in an established system. New routines face difficulties in such systems because their unfamiliarity may make actors choose those routines to which they are habituated (Ford, Ford, \& D'Amelio, 2008). The introduction of the Partner Portal into the network of Fritz Hansen created a new, direct line of communication between local dealers and Fritz Hansen headquarters (cf. the dotted line in Figure 1) which was intended to lead to a reconfiguration of activity allocation, information handling and communication between actors in the export marketing system. In this way, the project added a new set of routines to the existing roster already available to actors within a network. These new routines provided actors within the system with alternative ways of communicating and configuring activities and resources; yet, they were introduced into a system in which different mutually adapted sets of routines already co-existed. As the Partner Portal was introduced as a voluntary alternative to these existing 
routines and furthermore was never intended to completely replace existing patterns of communication and activity configuration, a key challenge was to convince different types of actors to substitute new for old and well-known routines.

\section{Analysis}

In the following, we will use the concept of network pictures to discuss different network actors' understandings of their network context and how these understandings affect their view on the Partner Portal. Case analysis showed the network pictures to differ widely between different levels of the network, resulting in different enactments of the inter-organizational routines required to ensure the coordination of activities and resources across actors in the network. Accordingly, the different network pictures endorse different framings of the change project in question, which is evident when actors throughout the network use their different understandings to make sense of the change project presented to them and when choosing whether to enact the requested change. In particular, we will illustrate and discuss how the evoking of different routines by different, individual actors creates organizational resistance and inhibits change within the network.

We will illustrate the different network pictures of routines at three different levels: Fritz Hansen headquarters, Fritz Hansen regional offices, and local dealers, using the statements of different individuals at each level in order to illustrate how individuals within the marketing system make sense of their surroundings and create idiosyncratic understandings of their own roles as well as those of others. We will also discuss how these individual understandings translate into the deliberate choice of certain interorganizational routines, which in turn create network rigidity, hamper change and lead to a redefinition of the change project.

\section{Pictures of network routines at Fritz Hansen headquarters}

Fritz Hansen aim to position themselves as a branded provider of exclusive furniture designed by internationally recognized architects and designers. For Fritz Hansen managers the overarching value creation logic is tightly related to delivering the narrative of exclusive Danish furniture design associated with world-renown design icons such as "The Egg" by Arne Jacobsen, which can be seen at the Museum of Modern Art in New York and other exclusive locations. More than mere pieces of furniture, the design furniture produced by Fritz Hansen express a modernist life style and a minimalist approach to interior decoration, branded as part of "Danish Design", which generally is associated with branded designer products such as Bang \& Olufsen products and PH lamps. Through the "Republic of Fritz Hansen" brand, the company aims at ensuring a tight alignment between the Danish design "feel" associated with quality and handcrafted exclusivity on the one hand and dealers and customers on the other. Users and dealers are supposed to see themselves as part of a world-spanning brand community in which they are related to Fritz Hansen and each other through a specific set of values and a keen interest in designer furniture. From Fritz Hansen's perspective, transferring this set of values from Denmark to another socio-economic context calls for strong ties of collaboration with selected partners who understand or at least complement the values that Fritz Hansen want their products to be associated with. Owing also to the exclusivity and price of the products sold, sales require personal presence and individual configuration of information and therefore Fritz 
Hansen rely heavily on the qualifications and dedication of their dealer network. They have therefore worked intensively with their strategy for cooperation with dealers. This strategy was devised in accordance with the decision to create a uniform, global image, supported by an international marketing strategy that differs very little from market to market. As part of this strategy, Fritz Hansen Allerød have developed a number of specific routines for the coordination of activities with their regional offices and these routines, in turn, are supported by a range of standardized information. In addition to obtaining a systematic relationship between Fritz Hansen Allerød and the range of regional offices, the purpose of this standardization of routines and information is also to enable a standardized coordination of activities between the regional offices and their local dealer network. As described above, the Partner Portal is part of this strategy and can be seen as an attempt to create a set of uniform routines to be used by all dealers.

One of the benefits associated with the Internet frequently mentioned in the media and among consultants during the dot.com boom concerned the possibilities of revitalizing marketing channels with the use of the Internet (Anderson \& Anderson, 2002). In this way, Fritz Hansen managers envisioned the Internet as a possibility for rationalizing export intermediation activities and standardizing information in order to facilitate the search for and provision of information to dealers:

...it should mean that much of the information previously handled by customer service concerning information about delivery times, locating invoices and things like that are now readily available. All these things they can actually log on and see for themselves now, but are they interested in that or do they prefer to talk to a person on the phone instead?

\section{VP branding and communication, Fritz Hansen, Allerød}

As is typical for Internet-related change projects, the main purpose of the project was to obtain better resource utilization and time savings in the relationships in Fritz Hansen's network, thus providing a deeper and better controlled exposure of marketing efforts in individual markets, beyond what had been conceivable within previous distribution systems (Amit \& Zott, 2001; Quelch \& Klein, 1996). Relieved of a number of administrative tasks, Fritz Hansen's regional offices would be able to redeploy resources for sales activities, which also the local managers saw as a potential benefit of the project:

...this is one important tool we are promoting because especially in terms of the best way of handling all the practical things - if all dealers in the future, in one year from now, are able to use the partner portal in the best way, I am sure we can save time in assisting them with some of the simple things, because all the practical things could be done in the partner portal.

VP Sales, Fritz Hansen

Introducing a new set of routines initiated a change process, which initially was a reflection of the divergent views of the different internal stakeholders at Fritz Hansen headquarters involved in developing the portal and organizing its global roll-out. These opinions were built on a shared understanding of the business model and the value creation opportunities of Fritz Hansen as described above. 
Initially, the launch of the Partner Portal project vis-à-vis the dealer network was the shared responsibility of the branding \& communication and the HR departments. The main responsibility for the Partner Portal, including the creation and maintenance of the majority of its contents, lay with the VP for branding and communication. Alongside him, the HR Manager was responsible for some of the contents, in particular elements related to product training. Although contents-wise this was a relatively small part of the portal, the HR department played an important role in the first stage of the creation and roll-out of the Partner Portal owing to the fact that at the time of development, the HR department was working on a training project which included different electronic tools and it therefore seemed natural to coordinate the two projects, as described by the HR Manager.

... as we were meeting with the partners for training anyway, it would be sheer madness not to use the possibility to introduce them to the Partner Portal as well. So you could say that the roll-out of the partner portal was re-planned and adapted to the [product] training. It has been a bit ... it has been dependent on where we have done [product] training...

HR Manager, Fritz Hansen $H Q$

In this way, the HR department was in effect given the operational responsibility for the first introduction of the Partner Portal towards local dealers; a decision which was anchored to a large extent in practical considerations, which in turn meant that the implementation of the Partner Portal somehow fell between two stools.

So suddenly you have to consider who has the ownership, who has to deliver something, and where is the development of the tool to be placed in the future. Who is to implement it and how do we make sure that it is kept alive. So it has become big. Not impossible, but I would say that it requires a lot of resources for it to be entirely optimum. Therefore, at the moment, it has ended up in an acceptable, but not optimum way.

HR Manager, Fritz Hansen $H Q$

This implementation model had two major consequences for the change process initiated. First, focus in the change process at least initially was almost exclusively on the dealer network due to the fact that the product training program, which the roll-out of the Partner Portal was integrated into, was targeted at external dealers and run by the HR department. A major implication of this network picture was that limited attention was devoted to the role of the regional offices in the implementation process. In fact, Fritz Hansen Allerød acted on the assumption that the use of the Internet in the relationship with their dealer network would have a number of benefits for all actors in the system and they implicitly assumed that the positive attitude to the Partner Portal at headquarters was shared by the regional offices. Scrutinizing the network understandings present at Fritz Hansen headquarters and at the regional offices, however, clearly shows that in reality headquarters and regional offices had widely differing understandings of the change project and of the roles of each network actor in it. These differences contribute with important parts of the explanation for why the change project at least initially did not produce the change behavior intended and how the project through the actions of the regional offices was reframed to fit the network pictures of not only dealers, but also the regional offices themselves. Looking back, 
the VP for IT described how this network view overlooked the role and responsibilities of Fritz Hansen's regional offices.

Then you could also look inside the company, as it could also have something to do with communication and training. But it will take some time to make it successful and be able to extract value from it. I don't know whether you read that [DIY retailer] got a price for their do-it-yourself courses. Because it is very logical that if the end user doesn't know how to hang wallpaper or tiles, then he will not sell as many tiles. Therefore, they have to train their own people how to do it to enable them to pass on the knowledge. And it is the same thing we do. That is, if our sales consultants are not able to train the partners, then we will have to make them more capable.

VP IT, Fritz Hansen, Allerød

\section{Pictures of network routines at the dealer level}

The vision and importance of the Partner Portal project was not shared by Fritz Hansen dealers. Interviews with dealers and architects on different markets lead to the same overall impression of a limited use of and willingness to use resources in adopting the Partner Portal. Furthermore, to the extent that the Partner Portal was used, this seemed to happen not as a result of the formal partner training, but upon thorough and repeated introductions and reminders by local sales consultants. In fact, in many interviews it was difficult to go into detailed discussions about how the different elements were used due to lack of experience with or interest in the portal on the part of the people interviewed.

Different dealers sum up their lack of need for the Partner Portal in different ways:

...certainly it is a good tool, but... I don't know exactly what it can lead to. It's practical; I don't know if it's going to...I can't see that it is going to make our turnover go up $50 \%$ or $100 \%$ or whatever. It's just practical. ... Well, the tool is not necessary ... I can use it as a reference, but I don't need it.

\section{Retail/contract dealer}

No, on the production side, no. I do not use it at all. There has not been any use for me as far as assisting with the...in regards of deliveries and expected arrival dates...

\section{Retail/contract dealer}

I do not think our sales staff does. Personally, I do not necessarily need the information that is on there. Some of the other sales staff might.

\section{Retail/contract dealer}

Taking the point of departure in the dealers' understanding of their network role relative to that of Fritz Hansen produced two key findings that contribute to understanding the resistance to change experienced at the dealer level. First, the different activity and resource constellations in which different network actors are embedded result in different actors defining their network contexts differently (Holmen \& Pedersen, 2003; Seo \& Creed, 2002). In our case, these differences meant 
that dealers defined the network context within which the change project was embedded differently from Fritz Hansen.

Second, dealers' understandings of the routines that the Partner Portal was meant to replace or complement turned out to be significantly different from those of Fritz Hansen. Whether they operate in the professional or the private sector, the dealers that Fritz Hansen sell through are always upmarket dealers with an expensive product range. Dealers typically carry a number of the same, globally present brands along with a number of smaller, international and national brands. Dealers, therefore, do not relate their critical value creation activities unambiguously to the Fritz Hansen concept. Rather, from their perspective, Fritz Hansen is just one supplier among several, who make it possible for them to provide value through satisfying their customers' need for interior decoration solutions. Supplies of design furniture are important for staging their role as solution providers, but suppliers are interchangeable and when it comes to a dealer's decision to pitch one supplier over another to a potential customer, elements such as for instance delivery times and discounts matter more than the stories behind the furniture. Furthermore, on many export markets, the general brand recognition of Fritz Hansen is still low and restricted to a very limited audience of connoisseurs. From this perspective, Fritz Hansen's marketing efforts are possible tools for dealers' sales representatives to use in convincing customers rather than a sine qua non element in their sales efforts.

In most cases, Fritz Hansen's products do not constitute a very large share of a dealer's total turnover. On the contrary, for a lot of partners, Fritz Hansen's products constitute only $5-10 \%$ of turnover and it is not unusual for dealers to have at least 2040 different suppliers. Hence, looking at a project like the Partner Portal from a dealer's perspective means looking at potentially learning how to use and getting to know the specific routines of a large number of IT solutions. This impression was confirmed in interviews with dealers who repeatedly linked their reluctance to using the Partner Portal to the limited share of turnover generated from Fritz Hansen's products.

It could be interesting if our work explodes in the future, and I get 10 orders [for Fritz Hansen products] every day.

\section{Retail/contract dealer}

If you had 24 sales of Fritz Hansen a day, then it's different ... [like] this week we did 500 Egg chairs and 300 PK 24 chaiselongs. ... Even if we were to triple our turnover, it still would be small ...; if it was the same turnover, but a lot more orders, then that would be a lot more practical.

\section{Retail/contract dealer}

...but we probably have a bit of a problem, we do not have many suppliers with whom we have a large turnover; 17 suppliers make up $85 \%$ of our turnover.

Contract dealer

As for the dealers' understanding of the inter-organizational routines that the Partner Portal was meant to replace or complement, there was a strong tendency on behalf of the dealers to want to stick to existing means of communication rather than use the Partner Portal and they repeatedly pointed out how they preferred to communicate 
with Fritz Hansen over the phone or face-to-face rather than using the Internet. In this regard, the export marketing system can be seen as characterized by a tendency to follow established patterns of behaviour (Sull, 1999). For the individual dealer, the established channel of communication, relying partly on the phone and partly on personal contact, had become routine and the partners felt neither the need nor had the incentive to change these routines, but would supplement them with selected information from the Partner Portal, when convenient. At the same time, from a sales point of view, many dealers did not feel that the job of selling Fritz Hansen furniture required much detailed information, apart from obvious information such as prices and delivery times. Although they appreciated the stories behind the furniture, they seemed to feel that they already knew these stories and therefore were not inclined to search for additional or new information. A dealer expressed this in a way that largely dismisses the potential value of an Internet-enabled information sharing system,

Once you know it, you know it. You do not really need to go back and refer to it.

\section{Retail/contract dealer}

The same dealer touched upon the issue of convenience, i.e. the fact that dealers may think that it is more convenient to use printed material in their dialogue with their customers.

It is almost always going to be quicker for us to grab that little book. All of our information right there in our hands, we can flip to the page and read it directly to the client rather than stopping, getting into our Internet program and pulling it up and then finding it on the website and typing in the password. That is never going to be as fast as picking up a book.

\section{Retail/contract dealer}

In other cases, such as for instance in the contract business, the sales process is more complex and requires detailed product information, but in many cases dealers or architects may then obtain such information directly from their Fritz Hansen sales representative, who may become heavily involved in the sales process for a certain project. In fact, some of these partners clearly preferred personal communication via phone or visits over using a website. They seemed unwilling to spend additional time using a new communication tool and simply chose the more convenient and wellknown way. For instance, in the case of an architect:

For us the personal contact is actually very important. We sometimes need help, for instance, in finding out if [a certain piece of furniture] is tolerant to disinfectants. Such questions I like to ask the sales consultant, because I believe it will save me time. Before I check it all myself. Of course, I try to use the shortest way, and then I naturally use the phone and maybe they reply, we have all that information on our website.

Interior designer

Another dealer summed up the same inclination to contact the sales consultant for information.

Last year, I downloaded a couple of pictures. I think that is all I have used it for. Otherwise, we have [name of sales consultant] just around the corner and I can 
enjoy the luxury of letting him come to me. ... [I use three sources of information:] Brochures, price lists and [name of sales consultant].

Contract deale

Dealers accordingly viewed the Partner Portal and Fritz Hansen's regional offices as interchangeable alternatives and as the local presence of Fritz Hansen grows stronger, the dealers may even see the Partner Portal as less relevant:

In the beginning we used Fritz Hansen's website to get all the possible information, because there was a lack of communication because Fritz Hansen Italia did not exist at that time. And so, the website was fundamental for us because the communication was really very, very difficult

Retail/contract dealer

\section{Pictures of network routines at the level of Fritz Hansen's regional offices}

The responsibility of Fritz Hansen's seven regional offices is to handle local sales, marketing and support activities. Their role in the value creation process is much akin to that discussed in the marketing literature on boundary spanning (Aldrich \& Herker, 1977; Walter, 1999). Serving as the critical link between Fritz Hansen headquarters and export markets, boundary spanners are in a double-selling position; they take on roles as mediators between constituencies with differently prioritized and sometimes conflicting goals. In doing so they have both an information processing function, selecting and interpreting information from local markets, as well as an external representation function through which Fritz Hansen headquarters' ideas and strategies are carried into local markets (Aldrich \& Herker, 1977). Thus, seen from the regional office manager's perspective, a critical process in value creation concerns smoothing out and buffering between differences among dealers and Fritz Hansen headquarters in order to avoid too many potential conflicts which may hinder work flows.

The way the different individuals at the regional level of the network framed the change project reflects this boundary-spanning role. On the one hand, sales consultants and managers are required to work with local dealers in ways consistent with the partner strategy of Fritz Hansen headquarters and in doing so they rely on centrally designed and produced information and guidelines. On the other hand, in the sales process, managers and consultants must also adapt information and processes to local markets and individual dealers in order to create and signal the commitment required to create local sales. An important criterion of success of a regional office is its ability to locate and develop the most appropriate local dealer network for Fritz Hansen. A major aspect of this process is to maintain a close dialogue and daily contact with the different dealers and architects. A local sales consultant described his task as simultaneously getting the order for Fritz Hansen and balancing the needs of different, competing customers:

From architects or from the customers, normally, the order goes to our partners, but sometimes I talk to them, and I work on the project with them and so we talk about projects and about defining the products; and sometimes we also talk about approximate prices, because it is a must for them to know, because if they want to order a 1000 chairs, it is very important. ... So it is my job to handle all this and to see to it that it goes in the right direction for Fritz Hansen, because our partner also carries other collections from other companies. I am a Fritz Hansen 
man only, and in the end I want to have our products in this project. So, I cannot always give all responsibility to my partner; so, I also have to call the architect and the customer to make sure that all partners are focusing on Fritz Hansen. ... ...if we have bigger projects, then most of your partners want to deal with this customer, and so you have to handle it the right way, so that in the end the customer is satisfied, the architect is satisfied and one of your partners is satisfied and all the other partners are not dissatisfied and that is very hard.

Sales consultant, Fritz Hansen

From this position as covering the middle ground between a number of network actors, the regional offices did not consider the Partner Portal project as an isolated project in the same manner that Fritz Hansen headquarters did. On the contrary, to both the regional VPs and the local sales consultants the Partner Portal was much more interwoven with the other activities they had to perform and it was interpreted as a relationship-building tool more than a tool for standardization and resource optimization:

...we were speaking [with the dealer] about all the information we are giving them and that we are going in the direction where we are investing a lot [in the local market] ... And we spoke about the Partner Portal, what are the possibilities, and we promoted the marketing bonus system ... it [i.e. the Partner Portal] is a tool that can help you in building more relationships. This is because they feel that this kind of tool is something dedicated to them.

VP Sales, Fritz Hansen

Therefore, with reference to the partnership strategy of Fritz Hansen the regional offices interpreted the Partner Portal not as a device to formalize and depersonalize the daily contact, but rather as a part of the personal contact. This was evident when a regional VP talked about the importance of not leaving the dealers alone with the Partner Portal, for instance.

What I try and work with my people is not so much push back and say 'look at the Partner Portal', but to more sit down with them and redirect their question through the Portal. They [i.e. the sales consultants] are sitting down with them, talking with them about the issue, showing them again how to do it, how to get on the system, talk about it, whether it's over the phone and talking through it, or physically sitting down with them, pending on the location.

VP Sales, Fritz Hansen

A consequence of this perspective is that the regional offices to some extent turned the Partner Portal into something that needed to be introduced gently to the dealers without creating too much disturbance to the status quo. In this picture, dealers are business partners who should be handled cautiously and, for instance, Fritz Hansen should not attempt to force dealers to use the Partner Portal. On the contrary, the regional offices saw their role as related to servicing their customers in the best possible way and the Partner Portal at times came close to being seen as interfering with the dealers' lives rather than helping them. This was clearly evident, for instance, in those instances where a local sales consultant would prefer to log on to the Partner Portal with his customer's password and ordering marketing material on his behalf rather than insisting on the dealer doing it himself. 
But I also use [the portal] with the codes of my partners, so I ask them and I know the password and so I can see the right marketing bonus they have or the last orders they had, and shipment and what is going on. If they call me again, please [name of sales consultant] can you order the marketing materials for us, because I do not know where to find it, you always change it and it is too boring for me. I say, okay, I will do it this time for you, but the next time we have an appointment, we have to look at the partner portal again.

Sales Consultant, Fritz Hansen

In this way, Fritz Hansen's regional offices to some extent reinforced the dealers' established routines. They accepted their role as the crucial link in the roll-out of the Partner Portal, however, framed the change project in a way so that it incorporated their own particular understanding of how they believed their customers would react to the project and in a way where it would not compromise their own reputation with these customers. Consequently, they were reluctant to disturb their customers' routines and they attempted to place as few demands as possible on them. In this way, the established routines of the system became self-confirming. Viewed from this perspective, the shift in routines that would follow from implementing the Partner Portal in the way initially intended was believed to have negative consequences for the ability of the local sales consultant to reach his task. Therefore, the behaviour of individuals at the regional level indirectly paved the way for a re-negotiation of the original change project in a way that took into account the attitudes of intended users to a larger degree, both in terms of portal contents and pace of implementation. This re-interpretation in fact altered the actual outcome of the change project. Figure 3 summarizes the network pictures at the three levels discussed.

\begin{tabular}{|c|c|c|c|c|}
\hline \multirow[b]{2}{*}{ Network level } & \multirow[b]{2}{*}{$\begin{array}{l}\text { Value creation } \\
\text { logic }\end{array}$} & \multicolumn{3}{|c|}{$\begin{array}{l}\text { Understanding of network roles } \\
\text { (in relation to change project) }\end{array}$} \\
\hline & & $\begin{array}{l}\text { Fritz Hansen } \\
\text { Allerød }\end{array}$ & $\begin{array}{l}\text { Fritz Hansen } \\
\text { regional offices }\end{array}$ & Dealers \\
\hline $\begin{array}{l}\text { Fritz Hansen } \\
\text { headquarters }\end{array}$ & $\begin{array}{l}\text { Provider } \\
\text { exclusive design } \\
\text { furniture. Attempt } \\
\text { to convey a } \\
\text { uniform, global } \\
\text { image through an } \\
\text { international } \\
\text { marketing strategy } \\
\text { applying similar } \\
\text { routines on all } \\
\text { markets. }\end{array}$ & & $\begin{array}{l}\text { Implicitly assumed } \\
\text { to share the view } \\
\text { of headquarters on } \\
\text { the Partner Portal } \\
\text { project and as } \\
\text { such to work in } \\
\text { favour of a shift in } \\
\text { routines between } \\
\text { headquarters and } \\
\text { dealers. }\end{array}$ & $\begin{array}{l}\text { The target of all } \\
\text { partnership efforts } \\
\text { including the } \\
\text { Partner } \\
\text { change portal } \\
\text { Dealers project. } \\
\text { expected are } \\
\text { benefit from the } \\
\text { change project } \\
\text { and to receive } \\
\text { standardization } \\
\text { efforts positively. }\end{array}$ \\
\hline $\begin{array}{l}\text { Fritz Hansen } \\
\text { regional offices }\end{array}$ & 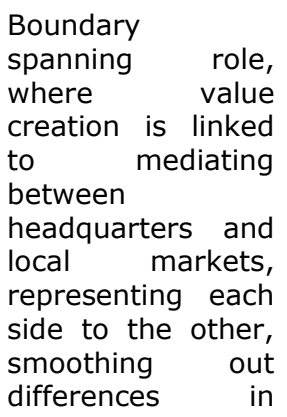 & $\begin{array}{l}\text { Appreciate } \\
\text { headquarters' } \\
\text { ideas behind the } \\
\text { change project, } \\
\text { but frame the } \\
\text { project as part of } \\
\text { local relationship } \\
\text { building activities, } \\
\text { hence to some } \\
\text { extent re- } \\
\text { interpreting the } \\
\text { idea behind the }\end{array}$ & & $\begin{array}{l}\text { Dealers are viewed } \\
\text { as resources that } \\
\text { must be protected } \\
\text { by catering to } \\
\text { their needs. They } \\
\text { are implicitly } \\
\text { endowed with the } \\
\text { right to dictate the } \\
\text { terms of the } \\
\text { change process } \\
\text { and their views } \\
\text { are supported. }\end{array}$ \\
\hline
\end{tabular}




\begin{tabular}{|c|c|c|c|}
\hline & $\begin{array}{l}\text { order to meet local } \\
\text { budgets }\end{array}$ & $\begin{array}{l}\text { change project to } \\
\text { fit their own logic. }\end{array}$ & \\
\hline Dealers & $\begin{array}{l}\text { Value creation is } \\
\text { linked to providing } \\
\text { the best solution } \\
\text { for the end-user } \\
\text { and in this process } \\
\mathrm{FH} \text { is only one of } \\
\text { many, } \\
\text { interchangeable } \\
\text { suppliers }\end{array}$ & $\begin{array}{l}\text { A 'distant' } \\
\text { provider of } \\
\text { product } \\
\text { information and } \\
\text { special requests to } \\
\text { be channelled to } \\
\text { dealers indirectly. }\end{array}$ & $\begin{array}{l}\text { The personal } \\
\text { relationship with } \\
\text { the sales consul- } \\
\text { tants is conveni- } \\
\text { ent and dealers } \\
\text { are not interested } \\
\text { in changing the } \\
\text { routines of this } \\
\text { relationship in } \\
\text { favour } \\
\text { increased of } \\
\text { standardization. }\end{array}$ \\
\hline
\end{tabular}

Figure 3. Summary of network pictures at Fritz Hansen headquarters, regional offices and local dealers.

\section{Discussion}

The traditional change management literature deals with both structural and cognitive aspects of organizational change. Change management in organizations is usually discussed as an "unfreeze-move-refreeze" sequence through which managers i) unfreeze by enacting change projects, ii) move a particular organizational order by installing transitions in organizational processes, structures and member values and iii) refreeze the new organizational order through stabilizing this change (Isabella, 1990). Structural aspects are typically related to issues of organizational design; how organizations may achieve a renewed fit with environmental opportunities and constraints through reorganizing task structures, information processing procedures and responsibilities, for instance (Burton \& Obel, 1998). Other schools of managerial thought focus on understanding organizational members' cognitive ability to make sense of change projects. As an organization may be described as a truce, balancing the interests of stakeholders (Cyert \& March, 1963), attempts to tamper with an existing order breeds resistance from some organizational members, who may find that changes create uncertainties or directly threaten achieved privileges. Resistance hinders organizational members or groups to accept or learn new routines (Argyris \& Schön, 1978). The case analysis, however, provides several insights concerning the challenges faced by managers seeking to install changes in business networks, which are not taken into account in either parts of this literature.

First, as pointed out in the analysis, managers at different network positions hold different network pictures of the routines for value creation. Consequently, they frame the process of value creation and their own role in this process differently, which means that change efforts - even though they intend to increase value creation and capture possibilities for the network in its entirety - are interpreted differently by managers positioned differently in the value creation network. Further reinforced by the fact that value creating activities transgress organizational boundaries, divergent network pictures are found no only across, but also within single organizations. For instance, in our case, the network pictures of routines and critical activities held by managers positioned at the regional level differ considerably from those of the managers at Fritz Hansen headquarters. Second, but also related to the first point, sources of resistance to change in business networks are somewhat different from those commonly discussed in the change management literature. In business networks, actors are engaged in several sets of business relationships and balancing 
the interests between actors and resource constellations comprises an important part of their activities (Gadde \& Håkansson, 1992). This also means that value creation logics and the corresponding logics for improving or altering activity constellations differ across network pictures. Such differing logics are bound to create incompatibilities between single actors across a network.

The case findings challenge two implicit assumptions of the change management literature: the role of managerial authority in firms as linked to ownership and the single-firm focus resulting from the disregard of external contingencies on change projects. The following discussion addresses how managed change in network settings challenges these assumptions.

\section{Management of change and the role of authority in firms versus business networks}

As shown in the case analysis, the implementation of the Partner Portal in its reduced form had the character of a negotiated outcome more than an implemented project as described in the change management literature. This points to the important role of managerial authority in change management. Installing organizational change calls for some measure of legitimized power or managerial authority. The change management literature typically borrows its conception of managerial authority from the general management literature. Here, authority is understood as the power vested in a managerial body and legitimized through formal hierarchy. Chandler (1977) expresses it in the following way: "Modern business is easily defined...it has two distinguishing characteristics: it contains many distinct operating units and is managed by a hierarchy of salaried employees". Most definitions of management therefore emphasize control as the locus of management (Shenhar \& Reiner, 1996). Due to the way it links management with legitimate authority and understands control as emanating from the formal organization of a firm - stipulating responsibilities, rights and roles - this definition, however, is too narrow to capture the specific characteristics of management in a network setting.

Management of relationships and managing in networks unfolds in a negotiated context, which is outside the span of ownership control. Even though some resources and activities indeed are under the control of management, a distinguishing feature of managing in networks is that execution of tasks cannot be dictated via managerial authority, as the creation of value using the internally controlled activities and resources depends on the co-alignment with activities and resources controlled by actors outside the organizational realm. This is true for the Partner Portal project, which was presented by Fritz Hansen headquarters as a voluntary alternative to existing routines and the implementation of which therefore depended on a certain alignment of the network understandings of e.g. headquarters and the dealer network. Weber (1961) defines legitimized authority as the probability that a directive or command with a specific content is followed by a given group of persons. Weber distinguishes between three forms of authority: legal (or formal), traditional and charismatic authority. Formal authority relates to organizational bureaucracy, while traditional authority relates to social order like, for instance, inheritance. Charismatic authority relates to the legitimate power given to particular actors based on their persuasive or rhetorical capabilities, providing them with the power of defining a situation and ascribing directions for others to follow. The latter notion of authority is interesting in the present context, as it does not assume the presence of institutional order (such a rights enforced by law) nor organizational order (such as in the 
organizational hierarchy) in order for resources and activities to be directed. In a negotiated context, relationship managers frame reality and use the expectations of others, who recognize the manager as trustworthy. This is the fundamental mechanism that provides access to resources and activities controlled by other actors in the network. A definition of management, which is consistent with the notion of charismatic authority, is offered by Barnard (1938), who defines management as the process, where managers seek to obtain results through convincing others to collaborate. In his view managerial authority rests stronger on the alter's acceptance of the managerial ego's leadership, rather than on the powers vested in him or her by their position in the organizational hierarchy.

Consequently, the change process when discussed in a network setting may pass through different stages than those discussed in conventional change management literature. For instance, the reactions of those whom a change initiative is targeted at have been described as going through four phases: initial denial, resistance, gradual exploration, and eventual commitment (Bovey \& Hede, 2001). When the ability to control the behavior of others through ownership is not present or when the probability that a directive is followed is low, however, the change process, for instance, cannot be expected to always lead to eventual commitment, which the case studied here clearly illustrates. What is furthermore interesting in the case is that even in relationships where formal ownership does exist, i.e. the relationships between headquarters and regional offices, established network logics and understandings of activity configurations and role divisions have enough influence upon the actions of individuals to undermine the control normally associated with ownership, resulting in actors at the regional level acting in ways that support the network pictures of the independent dealers more than those of headquarters. These reactions are consistent with the fundamental assumptions of social exchange theory, suggesting that economic exchange is inseparable from social exchange and evolves in relationships and with social capital literature, which depicts relationships as a resource for social action. Social exchange theory suggests that authority is legitimated by honouring one's obligations to other acts. In developing his famous norm of reciprocity, Blau states that: "An individual who supplies rewarding services to another obligates him. To discharge this obligation, the second must furnish benefits to the first in turn" (Blau, 1964:90-92).

Based on the above discussion we advance the following proposition.

Proposition 1: Compared with intra-organizational change, managed change in networks rests less on formal authority and to a higher degree on negotiation and communicative capabilities associated with charismatic authority

\section{Network picture complementarity as a condition for network change}

As pointed out, the change management literature largely ignores or treats only implicitly the existence and effect of external contingencies upon managerial initiative. The literature has a predominantly single firm perspective, which although it may incorporate or address different analytical levels internally in the organization seldom operates at a higher level of aggregation than the individual firm (Hughes, 2006). The case analysis presented here, however, shows that the co-existence within a network of different network pictures of routines creates a number of challenges to 
this single firm focus. The analysis also shows that it is not the mere existence of a wide range of different network pictures of routines that challenges the change management process, but just as much the extent to which these network pictures are similar. This points to the importance of overlap between co-existing network pictures to successfully implement changes in networks. The change management literature is concerned with designing change strategies that can help motivate individuals and groups to change in the direction that the actor initiating a change desires (Hayes, 2002). It implicitly assumes that a high degree of shared understanding between individuals will eliminate individual insecurity towards change and increase the likelihood of successful implementation. In a network setting, where individual actors are part of widely different activity and resource constellations, however, the challenge is to balance inevitable differences more that smooth them over, making the existing literature insufficient to understand network change. As illustrated in Figure 4 , our analysis indicates that the conditions for change may be more favourable when there is some, but not full overlap or similarity between network pictures as opposed to situations where network pictures of routines are either very dissimilar or highly aligned. Similar thoughts have been put forward in various discussions of the effect of network structure on inter-firm organizing (Uzzi, 1997), creativity (Perry-Smith, 2006; Shalley \& Gilson, 2004) and learning (Cohen \& Levinthal, 1990). Uzzi (1997), for instance, discusses how embeddedness in the shape of close and dedicated relationships improves inter-firm adaptation and commitment, information exchange and problem-solving capabilities, increasing the outcomes of exchange; yet also addresses how so called overembeddedness may turn those relationships into a liability, because it can also reduce an organization's ability to adapt to change. A similar graduation of the embeddedness of network pictures underlies Figure 4.

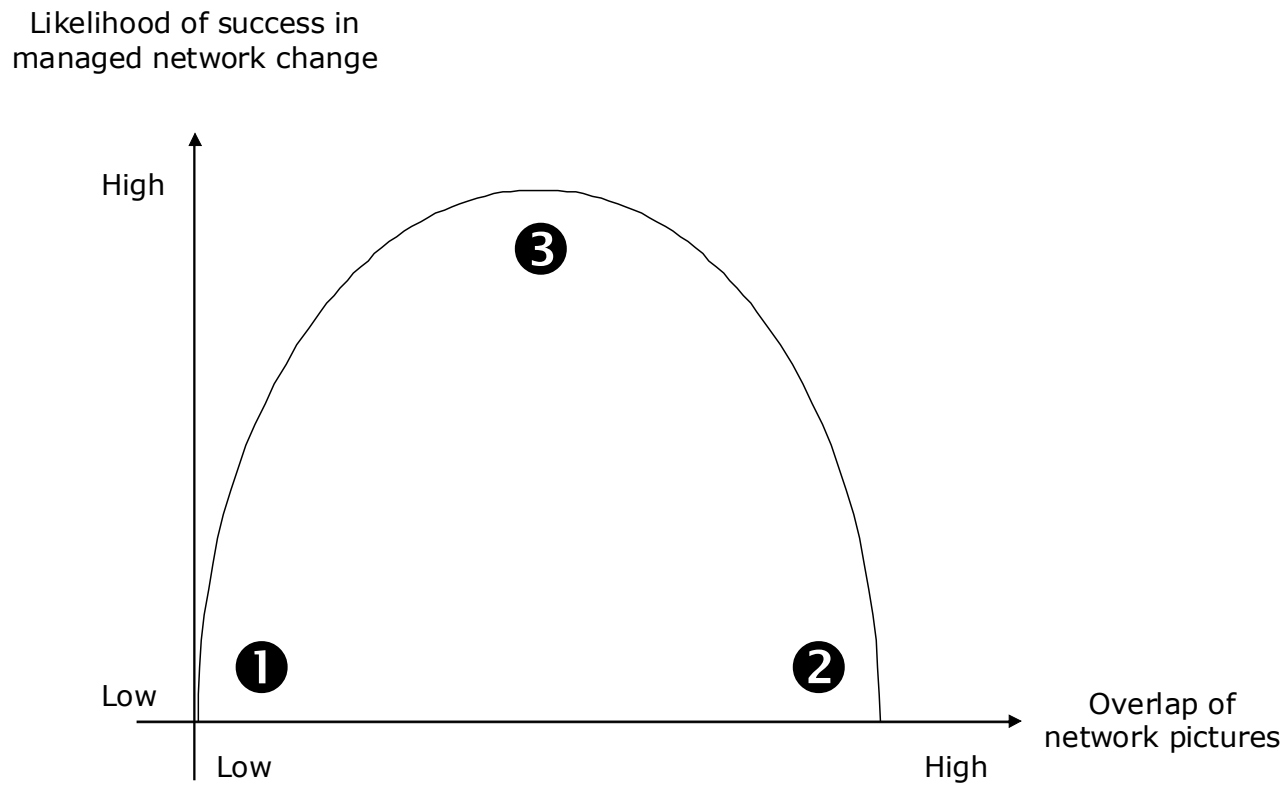

Figure 4: A proposed linkage between network picture similarity and successfully managed change

As illustrated in scenario 1, if the network pictures found within a network are dissimilar to an extent where no - or only a limited - shared understanding of a 
change project can be established, achieving the change outcome envisioned by the initiating actor may be impossible. In order for new network routines to be successfully implemented throughout a network, they must be actively selected by the recipient actors, who as discussed above are outside ownership control. Therefore, successfully managing network change "may hinge on the ability of actors to adopt and customize a potent or resonant frame for directing and mobilizing collective action" (Seo \& Creed, 2002:237). In other words, if a certain level of network support cannot be mobilized, changes will not take place. However, when network pictures are highly dissimilar, change projects that appear rational and fruitful to the initiating actor may lie so far outside the frame of reference of other actors that these actors are not receptive to these initiatives. Similar to discussions of absorptive capacity, the underlying reasoning is that a certain level of prior related knowledge is a prerequisite for an individual or an organization to be able to assimilate and apply knowledge from external sources (Cohen \& Levinthal, 1990). In our discussion, prior knowledge of the network pictures of other actors enables an actor to see and respond to a change project at least partially in accordance with the perspective of others. Without this capacity, it may be impossible for the change initiating actor to device a project that appeals sufficiently to its potential recipients. In the present case, such blocking of network change is illustrated by the substantial differences in the network pictures of Fritz Hansen headquarters and dealers on local markets, owing as described among other things to the fact that dealers include a wider range of suppliers in their network pictures (Holmen \& Pedersen, 2003).

In scenario 2, network pictures show a high degree of similarity and conditions for change are also not favourable. Although actors in this case have a shared understanding of activity configuration and role division within the network, successful implementation of a change project is made difficult by the fact that actors may support each other in holding on to established routines and activity configurations. This scenario is comparable to one with strong ties (Granovetter, 1973). In discussions of the role of tie strength on creativity, strong ties are seen as connecting similar individuals and lead to repetitive and redundant information. This, in turn, may constrain the knowledge base of these individuals (Perry-Smith, 2006; Perry-Smith \& Shalley, 2003). Accordingly, we argue that a scenario characterized by a high degree of network picture overlap may deprive actors of the access to diverse perspectives and heterogeneous viewpoints considered essential for creative or change capabilities in general. One consequence of such network picture similarity is that, over time, relationship-specific or network-specific routines may become institutionalized and act as constraints on network change, resulting in so called network inertia, i.e. "a persistent organizational resistance to changing interorganizational dyadic ties or difficulties that an organization faces when it attempts to dissolve old relationships and form new network ties" (Kim, Oh, \& Swaminathan, 2006:704). It has been discussed how such resistance resulting from the similarity of the network understandings of different actors may lead to "ossification of the status quo" (Henneberg, Mouzas, \& Naudé, 2006:412). In this way, the implementation of change activities is directed and restricted by network pictures shaped by earlier experience and which do not necessarily incorporate technological or other change in the surroundings of an individual actor (Öberg, Henneberg, \& Mouzas, 2007). Such network picture overlap is illustrated in the case by the shared understandings held by individual actors at Fritz Hansen headquarters of the roles of the different actors in value creation in the network, reflected in turn in the partnership 
strategy and the strategy for the use of Internet-enabled tools incorporating certain expectations to dealers and regional offices alike.

We believe that the best conditions for managed change in networks are found somewhere between the two extremes discussed above, i.e. in the space where different network pictures incorporate partly shared network understandings and therefore complement each other, cf. scenario 3 in Figure 4. Within this range, actors have sufficient insight into the roles and positions of other actors to devise change projects that incorporate the views of others, yet their activities and identities are still so separate that flexibility and network dynamics are preserved. In this respect, the scenario that holds the highest likelihood of successfully managing network change resembles that of a loosely coupled system (Weick, 1976) or, from a structural perspective, a system with many weak ties (Perry-Smith, 2006). Such systems are characterized by consisting of events or elements - in this case network pictures - that are responsive to one another, while at the same time maintaining individual separateness (Weick, 1976). This preservation of individual identity in particular can foster as well as sustain a system which is able to remain flexible and receptive to change. The underlying idea is that of requisite variety, i.e. that the existence of a richness of network pictures will make a network sufficiently diverse to be able to accurately reflect and accommodate change (Orton \& Weick, 1990; Weick, 1976). The value of such diversity is linked to the exposure of individual network pictures to diverse, alternative network pictures, facilitating flexible thinking and, hence, the capacity for change (Perry-Smith \& Shalley, 2003). In this way, the existence of loosely coupled - as opposed to tightly coupled or decoupled - network pictures may actually counteract the kind of network inertia addressed above. In the case studied here, the loose coupling between the network pictures of local sales representatives and managers at independent dealers, for instance, means that the former are able to remain sensitive to their local environment while promoting the Partner Portal, in effect re-constructing the change project to include the diversity of network pictures. In this way, network picture complementarity is both a precursor to and an outcome of network change, as it is partly created in the network as a result of the re-framing of the change project following from the enactment of co-existing network pictures (Orton \& Weick, 1990).

Based on the above discussion, we arrive at the following proposition.

Proposition 2: Managed change in networks has a higher likelihood of leading to the intended changes when the different network pictures of the routines subject to change are neither too distantly removed from one another nor entirely overlapping, but instead exhibit some degree of complementarity.

\section{Managerial implications and issues for further research}

The conditions for and challenges in managing change of organizational routines in network settings differ in several important respects from those highlighted in the change management literature. Our research suggests that a starting point for managers embarking upon change efforts in networks is to understand that these changes unfold in a negotiated context, where the authority and discretion over installing these change activities are limited. As stated by Ford et al., overcoming resistance to change therefore is a matter of engaging change recipients in "creating 
new realities, rather than in only prying them loose from old ones" (2008:372). Rather than defining change projects ex ante, managers need to define issues and agendas less rigidly and negotiate them with actors from their business network surroundings. In order to be able to do so, managers must challenge their own taken-for-granted assumptions regarding the routines for value creation in networks in order to understand how managers positioned differently in the network frame value creation routines. It is important to spend resources on grasping the network pictures of the actors who are recipients of these change efforts in order to identify possible overlaps and complementarities, because such complementarities form the backbone for any rhetorical effort towards change. As expressed by the famous philosopher Søren Kierkegaard: "If one is truly to succeed in leading a person to a specific place, one must first and foremost take care to find him where he is and begin there" (Hong \& Hong, 2000:460).

Another important managerial implication that can be derived from the present study concerns the crucial role of intrapreneurship at the boundary of the organization. In the case of Fritz Hansen, the regional managers were both policing change efforts as well as transforming the partner portal project so as to make it accessible and efficient by the other actors involved in the network. The crucial role of these actors in the process was overlooked by both the branding and communication and the human resource department, which targeted their change efforts directly at the dealer network. The regional sales offices at Fritz Hansen were supposed simply to communicate the intentions of the HQ departments. However, instead of simply following these processes they redefined important elements of the change projects, which allowed the project to progress forward although in a changed form. On a more general level, the regional managers diverted from the original script for implementing change, but shaped, re-negotiated and consequently reconstructed the change project within the broader intents and aspirations of the original project. This points to the role of the reactions of network actors as resources in securing the engagement, strength and ultimately the successful implementation of a change project (Ford, Ford, \& D'Amelio, 2008). Individuals, such as Fritz Hansen's regional managers, who from their position at the periphery of an organization are able to develop and exploit a large number of relationships with external actors, are in a position to enhance creativity and change (Perry-Smith, 2006). We therefore believe that the role of such boundary spanners not only in carrying out change efforts but also in actively redefining such projects is an underutilized resource in companies seeking to police change projects in networks. Understanding and using the powerful role of boundary spanners and allowing for considerable latitude of responsibility for (re)defining change projects in accordance with network participants' intentions and diverging frames of mind is critical for successful change efforts in business networks.

This paper has attempted to identify and discuss processes and dynamics of managing change in business networks. Based on our case analysis, we have proposed that managers attempting to deliberately install changes in network settings face a particular set of challenges not encountered in intra-organizational change management activities and therefore not contained within the traditional change management literature. We have identified divergences in network pictures and the negotiated nature of change management in networks as central traits. In order to develop our initial propositions further, however, comparative case analysis of change management in network settings is called for. 


\section{References}

Afuah, A. (2000). "How much do your co-opetitors' capabilities matter in the face of technological change?" Strategic Management Journal, 21, 387-404.

Alderson, W. (1957). Marketing behavior and executive action. Homewood, Illinois: Richard D. Irwin.

Aldrich, H., \& Herker, D. (1977). "Boundary spanning roles and organization structure", Academy of Management Review, 2(2), 217-230.

Amit, R., \& Zott, C. (2001). "Value creation in e-business", Strategic Management Journal, 22(6/7), 493-520.

Andersen, P. H. (2003). "The embeddedness of selfish routines: How routines are replicated in business networks", Industry and Innovation, 10(2), 159-177.

Anderson, P., \& Anderson, E. (2002). "The new e-commerce intermediaries", Sloan Management Review, 43(4), 53-62.

Argyris, C., \& Schön, D. A. (1978). Organizational learning: a theory of action perspective London: Addison-Wesley.

Barnard, C. I. (1938). The functions of the Executive: Harvard University Press.

Berger, P. L., \& Luckmann, T. (1966). The social construction of reality. A treatise in the sociology of knowledge. Harmondsworth, Middlesex: Penguin Books.

Blau, P. M. (1964). Exchange and power in social life. New York: John Wiley.

Bovey, W. H., \& Hede, A. (2001). "Resistance to organizational change: the role of cognitive and affective processes", Leadership \& Organization Development Journal, 22(8), 372-382.

Brennan, D. R., Turnbull, P. W., \& Wilson, D. T. (2003). "Dyadic adaptation in business-to-business markets", European Journal of Marketing, 37(11), 1636-1665.

Burton, R. M., \& Obel, B. (1998). Strategic Organizational Diagnosis and Design: Developing Theory for Application (2 ed.). Berlin: Springer Verlag.

Chandler, A. D. j. (1977). The visible hand: The managerial revolution in American Business. cambridge: Harvard University Press.

Chesbrough, H. W., \& Teece, D. J. (2002). "Organizing for innovation: When is virtual virtuous?" Harvard Business Review, 80(8), 127-134.

Cohen, W. M., \& Levinthal, D. A. (1990). "Absorptive capacity: A new perspective on learning and innovation", Administrative Science Quarterly, 35(1), 128152.

Cyert, R. M., \& March, J. G. (1963). A behavioral theory of the firm. Englewood Cliffs, NJ: Prentice-Hall.

Dyer, J. H., \& Singh, H. (1998). "The relational view: Cooperative strategy and sources of interorganizational competitive advantage", Academy of Management Review, 23(4), 660-679.

Economist Intelligence Unit. (2005). The 2005 e-readiness rankings. London: The Economist Intelligence Unit.

Feldman, M. S. (2000). "Organizational routines as a source of continuous change", Organization Science, 11(6), 611-629.

Feldman, M. S. (2003). "A performative perspective on stability and change in organizational routines", Industrial and corporate change, 12(4), 727-752.

Ford, D., Gadde, L.-E., Håkansson, H., \& Snehota, I. (2003). Managing business relationships. Second edition. West Sussex: Wiley. 
Ford, D., \& Håkansson, H. (2006). "The idea of business interaction", The IMP Journal, 1(1), 4-27.

Ford, J. D., Ford, L. W., \& D'Amelio, A. (2008). "Resistance to change: The rest of the story", Academy of Management Review, 33(2), 362-377.

Gadde, L.-E., \& Håkansson, H. (1992). "Analysing change and stability in distribution channels - A network approach". In B. Axelsson \& G. Easton (Eds.), Industrial networks. A new view of reality (pp. 166-179). London: Routledge.

Gadde, L.-E., \& Mattsson, L.-G. (1987). "Stability and change in network relationships", International Journal of Research in Marketing, 4(1), 2941.

Granovetter, M. S. (1973). "The strength of weak ties", American Journal of Sociology, 78, 1360-1380.

Hayek, A. (1945). "The use of knowledge in society", American Economic Review, $35,519-530$.

Hayes, J. (2002). The theory and practice of change management. Basingstoke: Palgrave Macmillan.

Henneberg, S. C., Mouzas, S., \& Naudé, P. (2006). "Network pictures: concepts and representations", European Journal of Marketing, 40(3-4), 408-430.

Holmen, E., \& Pedersen, A.-C. (2003). "Strategizing through analyzing and influencing the network horizon", Industrial Marketing Management, 32(5), 409-418.

Hong, H. V., \& Hong, E. H. (Eds.). (2000). The essential Kierkegaard. Princeton, NJ: Princeton University Press.

Hughes, M. (2006). Change management. A critical perspective London: Chartered Institute of Personnel and Development.

Håkansson, H. (1992). "Evolution processes in industrial networks". In B. Axelsson \& G. Easton (Eds.), Industrial networks. A new view of reality (pp. 129-143). London: Routledge.

Håkansson, H., \& Henders, B. (1995). "Network dynamics: Forces and processes underlying evolution and revolution in business networks". In K. Möller \& D. Wilson (Eds.), Business marketing: An interaction and network perspective (pp. 139-154): Kluwer Academic Publishers.

Håkansson, H., \& Snehota, I. (1995). Developing relationships in business networks. London: Routledge.

Isabella, L. A. (1990). "Evolving interpretations as a change unfolds: how managers construe key organizational events", Academy of Management Journal, 33(1), 7-41.

Johanson, J., \& Mattsson, L.-G. (1987). "Interorganizational relations in industrial systems: A network apporach compared with the transaction-cost approach", International Studies of Management Organization, 17(1), 34-48.

Kim, T.-Y., Oh, H., \& Swaminathan, A. (2006). "Framing interoganizational network change: a network inertia perspective", Academy of Management Review, 31(3), 704720.

Krackhardt, D. (1994). "Constraints on the interactive organization as an ideal type". In C. Heckscher \& A. Donnellon (Eds.), The post-bureaucratic organization (pp. 211-222). Thousand Oaks, CA: Sage Publications.

Kumar, N. K., Scheer, L., \& Kotler, P. (2000). "From Market Driven to Market Driving", European Management Journal, 18, 129-142. 
Kvale, S. (1995). "The social construction of validity", Qualitative Inquiry, 1(1), 1940.

Lei, D., \& Slocum, J. W. J. (1992). "Global strategy, competence-building and strategic alliances", California Management Review, 35(1), 81-98.

Orton, J. D., \& Weick, K. E. (1990). "Loosely coupled systems: A reconceptualization", Academy of Management Review, 15(2), 203-223.

Perry-Smith, J. E. (2006). "Social yet creative: The role of social relationships in facilitating individual creativity", Academy of Management Journal, 49(1), 85-101.

Perry-Smith, J. E., \& Shalley, C. E. (2003). "The social side of creativity: A static and dynamic social network perspective", Academy of Management Review, 28, 89-106.

Quelch, J. A., \& Klein, L. R. (1996). "The Internet and international marketing", Sloan Management Review, 37(3), 60-75.

Seo, M.-G., \& Creed, W. E. D. (2002). "Institutional contradictions, praxis, and institutional change: A dialectical perspective", Academy of Management Review, 27(2), 222-247.

Shalley, C. E., \& Gilson, L. L. (2004). "What leaders need to know: A review of social and contextual factors that can foster or hinder creativity", The Leadership Quarterly, 15, 33-53.

Shenhar, A. J., \& Reiner, J. (1996). "How to define management: A modular Approach", Management Development Review, 9(1), 25-31.

Snehota, I. (1993). "Market as Network and the nature of the Market Process", Foretagsekonomiska Institutionen, Uppsala University: Reprint Series 23.

Sull, D. L. (1999). "Why good companies go bad", Harvard Business Review, 77(4), 42-51.

Uzzi, B. (1997). "Social structure and competition in interfirm networks: The paradox of embeddedness", Administrative Science Quarterly, 42, 35-67.

Walter, A. (1999). "Relationship promoters: Driving forces for successful customer relationships", Industrial Marketing Management, 28(5), 537-552.

Weber, M. (1961). "The three types of legitimate rule". In A. Etzioni (Ed.), Complex organizations: A sociological reader: Holt, Rinehart \& Winston

Weick, K. E. (1976). "Educational organizations as loosely coupled systems ", Administrative Science Quarterly, 21, 1-19.

Öberg, C., Henneberg, S. C., \& Mouzas, S. (2007). "Changing network pictures: evidence from mergers and acquisitions", Industrial Marketing Management, 36, 926-940. 